\title{
Brief communication: The curious case of the large wood-laden flow event in the Pocuro stream (Chile)
}

\author{
Diego Ravazzolo $^{1,2}$, Luca Mao ${ }^{3,4}$, Bruno Mazzorana ${ }^{5,6,7}$, and Virginia Ruiz-Villanueva ${ }^{8}$ \\ ${ }^{1}$ Hydraulic and Environmental Engineering Department, Pontificia Universidad Católica de Chile, Santiago, Chile \\ ${ }^{2}$ Marine Energy Research and Innovation Center (MERIC), Santiago, Chile \\ ${ }^{3}$ Department of Ecosystems and Environment, Pontificia Universidad Católica de Chile, Santiago, Chile \\ ${ }^{4}$ Centro Nacional de Investigación para la Gestión Integrada de Desastres Naturales, Santiago, Chile \\ ${ }^{5}$ Instituto de Ciencias de la Tierra, Faculty of Science, Universidad Austral de Chile, Valdivia, Chile \\ ${ }^{6}$ Universidad Austral de Chile, RINA - Research Unit on Natural and Anthropogenic Risk, Valdivia, Chile \\ ${ }^{7}$ Millennium Nucleus CYCLO The Seismic Cycle Along Subduction Zones, Valdivia, Chile \\ ${ }^{8}$ Institute for Environmental Sciences, University of Geneva, Geneva, Switzerland
}

Correspondence to: Luca Mao (lmao@uc.cl)

Received: 2 May 2017 - Discussion started: 26 June 2017

Revised: 11 October 2017 - Accepted: 25 October 2017 - Published: 28 November 2017

\begin{abstract}
Large wood transported during extreme flood events can represent a relevant additional source of hazards that should be taken into account in mountain environments. However, direct observations and monitoring of large-wood transport during floods are difficult and scarce. Here we present a video of a flood characterised by multiple phases of large-wood transport, including an initial phase of wood-laden flow rarely described in the literature. Estimations of flow velocity and transported wood volume provide a good opportunity to develop models of large-woodcongested transport.
\end{abstract}

\section{Introduction}

Large wood is widely recognised as a positive element of a river system as they increase its ecological properties and functions (Gurnell, 2013). On the other hand, it represents a source of potential risk for humans when transported during high-magnitude flood events (Lucia et al., 2015). Especially in mountain rivers, floods tend to be short and intense, and are thus poorly investigated and rarely observed directly. During these types of events, large quantities of both sediments and large wood (commonly defined as logs $\geq 1.0 \mathrm{~m}$ in length and $\geq 0.1 \mathrm{~m}$ in diameter) are supplied into the channels and can cause serious harm to buildings and infras- tructure within the river corridor (Lucia et al., 2015; Steeb et al., 2017). In order to assess and mitigate risks associated to large-wood transport in rivers, it is crucial to properly understand the dynamics of wood during floods (RuizVillanueva et al., 2016). In small high-gradient streams, logs are intrinsically more stable and tend to move only during high-magnitude events in contrast to lowland rivers (Wohl and Jaeger, 2009), and the volume of logs transported depends on the land-use and mass wasting processes occurring at the scale of a drainage basin and riparian areas along the river network (Lucia et al., 2015). Although empirical formulas have been developed to estimate the potential volume of wood transported during floods (e.g. Rickenmann,1997; Comiti et al., 2016), these are heavily dependent on wood supply conditions and of little predictive power, mainly due to the lack of field data. Indeed, field observations of largewood dynamics during floods are scarce. However, recent advances in monitoring techniques allow us to track or observe wood dynamics using metal tags (Iroumé et al., 2015), active and passive radio frequency identification tags (Schenk et al., 2014), GPS devices (Ravazzolo et al., 2015) and video cameras (Benacchio et al., 2017).

In this paper we report on an extreme flood event that occurred in February 2017 in the Pocuro stream (Central Chile). The event was captured by a local resident with a smartphone and the video was posted on social networks. The video 


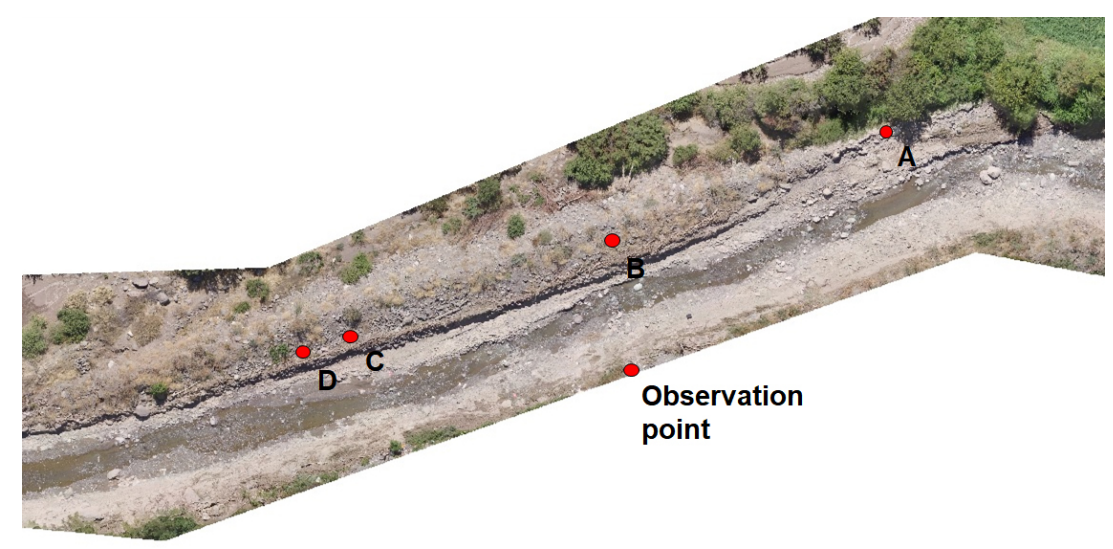

Figure 1. Composite image of the study reach of the Pocuro stream, showing the location of the point from which the video was taken and the control points used to calculate the flow velocity. The flow is from right to left.

shows that the front of the event was characterised by mass transport of large logs, more similar to a debris-flow than congested transport of floating logs, a phenomenon which has only been rarely reported in the literature. Evidence on flow velocity and the volume of large wood transported by the event has been gathered from the video. This data set is presented in order to improve the current understanding of flood processes in forested mountain streams and may represent a significant set of data which is used to develop and test a numerical model able to simulate such an extreme event.

\section{Analysis of the 25 February 2017 event}

In the second half of February 2017, a series of convective rainfall events occurred in central Chile, producing several flash floods in mountain rivers. These events resulted in considerable loss of property. Several villages had to be evacuated, and five people lost their lives. The event described in this work occurred on the Pocuro stream, a stream located near the city of Los Andes, approximately $60 \mathrm{~km}$ north of Santiago, on the 25 February 2017. At the study reach, the basin drains an area of $227 \mathrm{~km}^{2}$, which is highly mountainous (minimum and maximum elevation of 870 and $3550 \mathrm{~m}$ a.s.1.). The basin is mainly covered by sparse bushes and bare land $(73 \%)$, and only $16 \%$ of the basin is covered by forest. The mean annual precipitation in the basin is around $250 \mathrm{~mm}$, with a strong Mediterranean regime, although convective rainfall events in late summer are not uncommon in central Chile.

The 25 February event in the Pocuro stream caused several problems of accessibility, access to drinkable water and the loss of one life. The event was triggered by relatively intense precipitation $\left(15 \mathrm{~mm} \mathrm{day}^{-1}\right.$, registered by the Vilcuya station located within the basin). The event was recorded by a local resident using a smartphone, and the video was quickly posted on social networks.
The video was downloaded as an MP4 file at the maximum possible resolution (see Supplement). Two weeks after the event, an intense field investigation allowed us to identify the exact position from which the video was taken $\left(32^{\circ} 53^{\prime} 11.19^{\prime \prime} \mathrm{S}-70^{\circ} 35^{\prime} 18.99^{\prime \prime} \mathrm{W}\right)$. Local residents reported that the event was a flash flood and characterised by huge amount of transported logs but did not recall the occurrence of following surges or pulses of log transport. However, several interviewees reported that a similar event (albeit with significantly less amount of transported wood) occurred in 2016 without major adverse consequences. The longitudinal profile and several cross sections of the reach visible from the video were surveyed using a laser distance metre with clinometer and a prism pole. Also, a series of photos was taken using a drone survey. The reach was straight and featured a regular trapezoidal shape (due to river engineering carried out the year before for flood protection purposes), with a slope of $0.04 \mathrm{~m} \mathrm{~m}^{-1}$ (Fig. 1). A grid-by-number survey revealed that the channel bed had a $D_{50}$ of $50.5 \mathrm{~mm}$. High water marks (i.e. wood deposits and marks left by mud) were clearly visible and allowed us to calculate that at the peak of the event the channel width was around $14 \mathrm{~m}$, with a wetted area of about $25 \mathrm{~m}^{2}$. The distances between four control points (boulders or distinct bushes clearly visible on the video and straightforwardly recognisable in the field) were taken using the laser distance metre.

The video was taken by looking at the upstream and downstream directions twice. For this reason, the full video was divided into four parts: (a) looking upstream (0 to $45 \mathrm{~s}$ ), (b) looking downstream (45 to $61 \mathrm{~s}$ ), (c) looking upstream (61 to $84 \mathrm{~s}$ ) and (d) looking downstream (84 to $94 \mathrm{~s}$ ). Two control points were always visible on each portion of the video (A-B and $\mathrm{C}-\mathrm{D}$, Fig. 1). Control points $\mathrm{A}$ and $\mathrm{B}$ were used to calculate flow velocity for the portions of the video looking upstream, whereas control points $\mathrm{C}$ and $\mathrm{D}$ for the portions of the video looking downstream from the observation point (see Fig. 1). The video lasts $94 \mathrm{~s}$, but for the sake of 


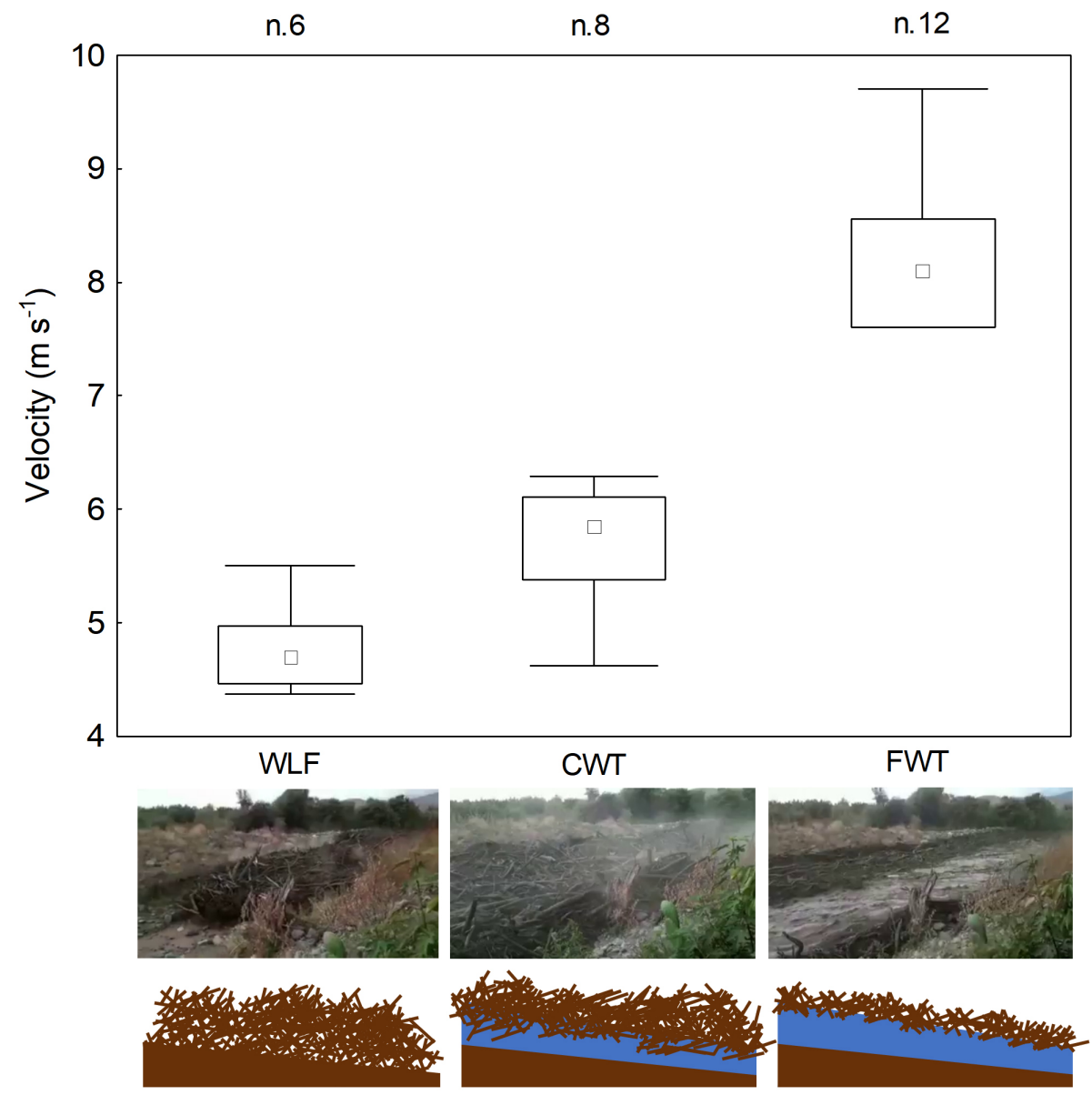

Figure 2. Mean velocity of three different portions of the event: (a) the front of the event, where logs where transported as a dry mass (woodladen flow; WLF); (b) the middle of the event, where logs were highly congested but clearly floating on water (congested wood transport, CWT) and (c) after the passage of the front, where logs were floating on water (floating wood transport, FWT).

the following analysis, the first $22 \mathrm{~s}$ (before the flow arrives to the upstream control point) were eliminated.

The freeware Pelscope software (www.codecian.com/ pelscope.html) was used to produce frames at $3 \mathrm{~Hz}$. Then, we identified features clearly visible on several frames (e.g. a distinctly coarser or protruding logs) in order to calculate the surface flow velocity.

\section{Results and discussion}

The video shows that a huge volume of logs was transported in the Pocuro stream, and that the arrival of the front of the event was very impulsive. The video reveals that liquid discharge was almost negligible in the channel before the arrival of the large wood front. The front was characterised by logs of different sizes clearly moving as a mass pushed from behind and not floating on water. The front moved at a mean velocity of $4.7 \mathrm{~m} \mathrm{~s}^{-1}$ (Fig. 2), and this first phase of the event was named wood-laden flow (WLF) for its appearance and behaviour. The front moved at a speed close to $5 \mathrm{~m} \mathrm{~s}^{-1}$ for approximately $12 \mathrm{~s}$. After the first WFL phase, the velocity increased sensibly (to around $5.8 \mathrm{~m} \mathrm{~s}^{-1}$ ) for the following $16 \mathrm{~s}$. During this second phase of the event (named congested wood transport, CWT), the surface of the log raft appears to feature waves, suggesting that the logs were floating on water, which would be consistent with the increase of mean velocity. On a third phase (called floating wood transport, FWT), the mean surface velocity was significantly higher $\left(8.1 \mathrm{~m} \mathrm{~s}^{-1}\right)$. The $\operatorname{logs}$ were floating as a continuous raft but occupying only a portion of the cross section. The video does not allow any information on bedload transport to be inferred during the event. However, post-event field observations revealed that the channel remained virtually unchanged after the flood, as little patches of herbaceous vegetation were still growing in most of the cross section.

Based on a series of flume experiments, Braudrick et al. (1997) described the dynamics of log transport in rivers as congested, semi-congested and uncongested, the first one reporting the case in which logs are floating with intense piece-to-piece interactions and occupying more than a third 
of the channel area. In the case of the Pocuro stream, only the third phase of the event could thus be classified as congested transport, the first two phases being fundamentally different, because it is more similar to a mass or a debris flow-type of transport, with imbricated structure and partly collisional regime. Braudrick et al. (1997) presented a preliminary attempt to model the mobility of uncongested individual pieces of wood, highlighting the challenges in modelling complex interactions between logs and characterising the congested transport mode. Although recent efforts in modelling allow the production of reliable 2-D descriptions of individual log entrainment, transport and deposition in river systems (e.g. Mazzorana et al., 2011; Ruiz-Villanueva, 2014), the congested wood transport is far from being properly understood. Previous works reported that wood transport in mountain streams is likely to occur under congested conditions, and that debris flows are important in supplying wood material to main rivers (e.g. Nakamura et al., 2000; Wohl et al., 2009). However, despite some early mention of events transporting large amounts of wood in highly congested ways (e.g. Swanston and Swanson, 1976; Ruiz-Villanueva and Stoffel, 2017), a proper description of a wood mass moving as a debris-flow has not been fully reported in the literature yet (e.g. Ruiz-Villanueva et al., 2017). During the first phase of the event in the Pocuro stream (WLF), the mass of logs appeared to not be saturated with water; thus log collisional and frictional stresses might be expected to dominate, and the phenomena was likely moving as a rock avalanche. Also, the video shows that some longer elements appear to snag on the channel bed and act as pivoting elements, thus likely increasing fictional stress on the channel bed. Instead, during the second phase (CWT) the water content appeared to be much higher, likely increasing the solid-fluid interactions and the role of viscous forces in the motion of the mass. Current debris-flow models consider sediment the only component of the solid fraction, but logs can definitely play a major role in determining the rheology of these phenomena. Because the contribution of debris-flows to the wood budget of extreme events can be very relevant (see Lucia et al., 2015; Steeb et al., 2017), there is an urgent need to develop better models for large-wood-congested transport and even more of a need to consider mass transport of large wood in the models.

The availability of the channel geometry and the mean velocity of the wood mass allowed us to estimate the volume of wood transported during the event. Even considering only the first two phases of the event (i.e. WLF and CWT) and assuming that a third of the cross section was occupied by water, the estimated volume of transported wood is around $3680 \mathrm{~m}^{3}$. This volume is remarkably high, provided that in a recent review, Ruiz-Villanueva et al. (2016) reported that large wood exported from basins $>100 \mathrm{~km}^{2}$ generally ranges from 500 to $4000 \mathrm{~m}^{3}$ (Fig. 3). To put this value into perspective, the volume of large wood measured within the channel after the event accounts for only $0.3 \mathrm{~m}^{3}$ hectare ${ }^{-1}$ of sur-

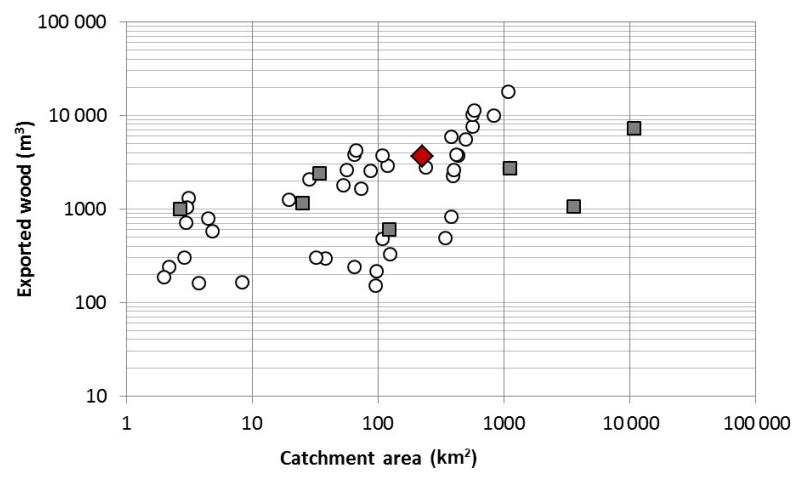

Figure 3. Large-wood volume exported from different watersheds by single flood events. The figure is adapted from Ruiz-Villanueva et al. (2016) and includes data presented by Steeb et al. (2017; white circles) and a number of other sources (see Ruiz-Villanueva et al., 2016). The red diamond is the Pocuro event.

veyed channel area (mean log length and diameter of 1.53 and $0.08 \mathrm{~m}$, respectively), which is well below other values available in the literature for basins of comparable size (see Ruiz-Villanueva et al., 2016). All evidence thus suggests that this was an extreme high-magnitude event, and that virtually all transported logs were recruited from upstream reaches or mass wasting processes at the basin scale, making the estimation of large-wood transport from in-channel large-wood deposition very difficult in these conditions. This evidence is in concert with recent studies (e.g. Lucia et al., 2015; Streeb et al., 2017), which proved that most of the large wood transported during extreme events in mountain rivers were recruited from the basin; thus the in-channel wood load was a poor proxy for estimating potential hazards due to wood during extreme events. In the case of the Pocuro stream, further investigations into recruitment mechanisms could shed further light on the origin of the phenomena. The video allows us to appreciate that most of transported logs lacked fresh branches. Also, all of the logs found in the channel at the post-event surveys were not freshly recruited, and most of them were in an advanced state of decay. This would suggest that the uptake of trees from landslides and bank erosion was probably a minor source of logs during the event. Local residents claim that several tributaries in the lower part of the basin were left unmanaged and featured large volumes of in-channel wood, which was eventually transported to the main channel during the flood event. However, this should be verified in the field by assessing the presence and extent of mass movement or bank erosion that could have provided a fresh source of large wood during the event. Indeed, exploring the most likely sources of large wood at the basin scale would shed some light on the processes and temporality involved in the recruitment and transport of logs during the event. It is also worth noticing that the massive amount of wood flushed during the event $\left(3680 \mathrm{~m}^{3}\right)$ was transported within $29 \mathrm{~s}$, which accounts for a mean wood transport dis- 
charge of around $85 \mathrm{~m}^{3} \mathrm{~s}^{-1}$. This value is virtually not comparable with any other in the literature, as the transport of large wood is rarely observed and monitored, at least under congested transport conditions. To put it into perspective, the liquid discharge after the wooden front was calculated to be around $200 \mathrm{~m}^{3} \mathrm{~s}^{-1}$ (and a 1-D simulation with Hec-Ras confirmed this value), so that more than a third of the average discharge of the rising limb of the event was composed of wood.

\section{Final remarks}

To the best of our knowledge, this is the first reported observation of a wood-laden flow, i.e. an event characterised by congested wood transported, not as floating material but as a rather dry mass of logs. These types of events can be very important in mountain environments due to their direct impacts on infrastructures and their contribution to wood budgets of lowland rivers but are particularly difficult to observe and monitor as they are arguably intense, sudden and highly unpredictable.

- There are multiple open questions about the genesis and the dynamics of the event, such as the origin of the logs (basin vs. upstream reaches or minor tributaries), the fate of the wood material and the best hazard management strategy to be adopted, which are worth exploring in the area.

- The availability of channel geometry and surface flow velocity data provides an unprecedented opportunity to develop and calibrate models of large-wood-congested transport.

- Monitoring large-wood transport in rivers is still very challenging. Recent use of active transmitters (Ravazzolo et al., 2015) or ground cameras (Benacchio et al., 2017) provided useful insights into the dynamics of logs during floods, but are still experimental. The present paper shows that conventional methods may be successfully complemented by participatory sensing (Michelsen et al., 2016) and that despite some relatively minor issues (i.e. access to internet technology, geographic and demographic biases) it offers an interesting alternative for collecting relevant information of infrequent events in remote areas.

Data availability. The video of the event is available as Supplement.

\author{
The Supplement related to this article is available \\ online at https://doi.org/10.5194/nhess-17-2053-2017- \\ supplement.
}

Competing interests. The authors declare that they have no conflict of interest.

Acknowledgements. The research was supported by the projects Fondecyt Regular 1170657, Fondecyt Postdoctorado 3170011, Redes-150153, and also by an internal fund of the Universidad Austral de Chile (Dirección de Investigación y Desarrollo - DID) made available by Eduardo Jaramillo. We thank Nicolas Delgado for giving us the permission to use and share the video of the event in the Pocuro stream. We also thank Felipe Parada (DGA) for providing rainfall data and Felipe Dreves for flying a drone over the study reach.

Edited by: Mario Parise

Reviewed by: Frederick Swanson and one anonymous referee

\section{References}

Benacchio, V., Piégay, H., Buffin-Bélanger, T., and Vaudor, L.: A new methodology for monitoring wood fluxes in rivers using a ground camera: potential and limits, Geomorphology, 279, 4458, https://doi.org/10.1016/j.geomorph.2016.07.019, 2017.

Braudrick, C. A., Grant, G. E., Ishikawa, Y., and Ikeda, H.: Dynamics of wood transport in streams: A flume experiment, Earth Surf. Proc. Land., 22, 669-83, https://doi.org/10.1002/(SICI)10969837(199707)22:7<669::AID-ESP740>3.0.CO;2-L, 1997.

Comiti, F., Lucía, A., and Rickenmann, D.: Large wood recruitment and transport during large floods: a review, Geomorphology, 269, 23-39, https://doi.org/10.1016/j.geomorph.2016.06.016, 2016.

Gurnell, A. M.: Wood in fluvial systems, in: Treatise on Geomorphology, vol. 9, edited by Shroder, J., and Wohl, E., chap. 236, 163-188, Academic Press, San Diego, CA, https://doi.org/10.1016/B978-0-12-374739-6.00236-0, 2013.

Iroume, A., Mao, L., Andreoli, A., Ulloa, H., and Ardiles, M. P.: Large wood mobility processes in low-order Chilean river channels, Geomorphology, 228, 681-693, https://doi.org/10.1016/j.geomorph.2014.10.025, 2015.

Lucía, A., Comiti, F., Borga, M., Cavalli, M., and Marchi, L.: Dynamics of large wood during a flash flood in two mountain catchments, Nat. Hazards Earth Syst. Sci., 15, 1741-1755, https://doi.org/10.5194/nhess-15-1741-2015, 2015.

Mazzorana, B., Hübl, J., Zischg, A., and Largiader, A.: Modelling woody material transport and deposition in alpine rivers, Nat. Hazards, 56, 425-449, https://doi.org/10.1007/s11069-0099492-y, 2011.

Michelsen, M., Dirks, H., Schulz, S., Kempe, K., Al-Saud, M., Schüth, C: YouTube as a crowd-generated water level archive, Sci. Total Environ., 568, 89-195, 2016.

Nakamura, F, Swanson, F. J, and Wondzell, S. M.: Disturbance regimes of stream and riparian systems: a disturbance-cascade perspective, Hydrol. Process., $14, \quad 2849-2860$, https://doi.org/10.1002/10991085(200011/12)14:16/17<2849::AID-HYP123>3.0.CO;2-X, 2000.

Ravazzolo, D., Mao, L., Picco, L., and Lenzi, M. A.: Tracking $\log$ displacement during floods in the Tagliamento River using 
RFID and GPS tracker devices, Geomorphology, 228, 226-233, https://doi.org/10.1016/j.geomorph.2014.09.012, 2015.

Rickenmann, D.: Schwemmholz und Hochwasser, Wasser Energie Luft, 89, 115-119, 1997.

Ruiz-Villanueva, V. and Stoffel, M.: Frederick J. Swanson's 19761979 papers on the effects of instream wood on fluvial processes and instream wood management, Prog. Phys. Geog., 41, 124133, https://doi.org/10.1177/0309133317692411, 2017.

Ruiz-Villanueva, V., Bladé, E., Sánchez-Juny, M., MartiCardona, B., Díez-Herrero, A., and Bodoque, J. M.: Twodimensional numerical modeling of wood transport, J. Hydroinform., 16, 1077, https://doi.org/10.2166/hydro.2014.026, 2014.

Ruiz-Villanueva, V., Piégay, H., Gurnell, A. M., Marston, R. A., and Stoffel, M.: Recent advances quantifying the large wood dynamics in river basins: new methods and remaining challenges, Rev. Geophys., 54, 611-652, https://doi.org/10.1002/2015RG000514, 2016.

Ruiz-Villanueva, V., Galatiotto, N., Bürkli, L., and Stoffel, M.: Understanding triggers and dynamics of wood-laden flash floods in mountain catchments: examples from the Zulg River (Switzerland), Geophysical Research Abstracts, Vol. 19, EGU201716792, 2017.
Schenk, E. R., Moulin, B., Hupp, C. R., and Richter, J. M.: Large-wood budget and transport dynamics on a large river using radio telemetry, Earth Surf. Proc. Land., 39, 487-498, https://doi.org/10.1002/esp.3463, 2014.

Steeb, N., Rickenmann, D., Badoux, A., Rickli, C., and Waldner, P.: Large wood recruitment processes and transported volumes in Swiss mountain streams during the extreme flood of August 2005, Geomorphology, 279, 112-127, https://doi.org/10.1016/j.geomorph.2016.10.011, 2017.

Swanston, D. N. and Swanson, F. J.: Timber harvesting, mass erosion, and steep land forest geomorphology in the Pacific Northwest, in: Geomorphology and Engineering, edited by: Coates, D. R., Dowden, Hutchinson, and Ross. Inc, Stroudsburg, PA, 199-221, 1976.

Wohl, E. and Jaeger, K.: A conceptual model for the longitudinal distribution of wood in mountain streams, Earth Surf. Proc. Land., 34, 329-344, https://doi.org/10.1002/esp.17222009, 2009.

Wohl, E., Ogden, F. L., and Goode, J.: Episodic wood loading in a mountainous neotropical watershed, Geomorphology, 111, 149-159, 2009. 